\title{
Los pliegues de la extranjería. Familia, viaje y archivo en La tierra empezaba a arder (2019) de Cynthia Edul
}

\author{
Marcos Germán Seifert
}

Seifert, M. G. (2022). Los pliegues de la extranjería. Familia, viaje y archivo en La tierra empezaba a arder (2019) de Cynthia Edul. Revista de Filología y Lingüística de la Universidad de Costa Rica, 48(1), e48387. doi: https://doi.org/10.15517/rfl.v48i1.48387

\section{(9) $\mathbb{P Q \Theta}$}

Doi: https://doi.org/10.15517/rfl.v48i1.48387

URL: https://revistas.ucr.ac.cr/index.php/filyling/index 
Revista de Filología y Lingüística de la Universidad de Costa Rica

ISSN: 0377-628X

ISSN: 2215-2628

filyling@gmail.com

Universidad de Costa Rica

Costa Rica

\section{Los pliegues de la extranjería. Familia, viaje y archivo en La tierra empezaba a arder (2019) de Cynthia Edul}

Seifert, Marcos Germán

Los pliegues de la extranjería. Familia, viaje y archivo en La tierra empezaba a arder (2019) de Cynthia Edul

Revista de Filología y Lingüística de la Universidad de Costa Rica, vol. 48, núm. 1, e48387, 2022

Universidad de Costa Rica, Costa Rica

Disponible en: https://www.redalyc.org/articulo.oa?id=33268016011

DOI: https://doi.org/10.15517/rfl.v48i1.48387

\section{(c) $\underset{\mathrm{BY}}{(\Theta \mathrm{NO}} \mathrm{No}$}

Esta obra está bajo una Licencia Creative Commons Atribución-NoComercial-SinDerivar 3.0 Internacional. 
Los pliegues de la extranjería. Familia, viaje y archivo en La tierra empezaba a arder (2019) de Cynthia Edul

\section{The Foreignness Folds. Family, Travel and Archive in Cynthia Edul's La tierra empezaba a arder (2019)}

Marcos Germán Seifert

Universidad Nacional de Hurlingham, Buenos Aires,

Argentina

marcseifert19@gmail.com

iD https://orcid.org/0000-0001-7322-7714
DOI: https://doi.org/10.15517/rfl.v48i1.48387

Redalyc: https://www.redalyc.org/articulo.oa? $\mathrm{id}=33268016011$

Recepción: 26 Abril 2021

Aprobación: 24 Junio 2021

\section{Resumen:}

La tierra empezaba arder (2019) de Cynthia Edul (Argentina, 1979) aprovecha de múltiples maneras el motivo del regreso a la tierra de los antepasados: como perspectiva y eco de la escritura, incluso como forma que asume la narración. La novela conecta la condición fantasmal e inestable del retornante con una cuestión urgente del presente: la de los migrantes, los refugiados, las víctimas del terror sistemático, los desposeídos. Si bien el relato familiar es lo que permite conectar el drama íntimo y el desastre humanitario, social y político, la escritura no descansa en esta relación como algo dado, sino como producto de un trabajo de la mirada, una disposición poética, y, al mismo tiempo, un impulso explicativo que busca visibilizar causas, rastrear datos históricos y establecer redes. El pliegue entre lo familiar y lo político se logra en la narración desde una posición de extranjería que habilita el montaje de un "archivo heterogéneo" para dar cuenta de las huellas y persistencias del pasado. El libro recupera de la idea de pliegue una lógica que permite resignificar el ocultamiento como un modo renovado de la exposición.

Palabras ClaVe: regreso, extranjería, fotografías, archivo, refugiados.

\section{ABstract:}

La tierra empezaba arder (2019) by Cynthia Edul (Argentina, 1979) makes use of the motive of the return to the ancestor's homeland in multiple ways: as a perspective and echo of the writing, even as the form assumed by the narrative itself. The novel connects the ghostly and unstable condition of the returnee with an urgent question of the present: that of migrants, refugees, victims of systematic terror, the dispossessed. Although the family story is what makes possible to connect the intimate drama and the humanitarian, social and political disaster, writing does not rest on this relationship as something given, but as a product of a work of the gaze, a poetic disposition, and, at the same time, as an explanatory impulse that seeks to make visible causes, that traces historical data and establishes networks. The fold between the familiar and the political is achieved in the narrative from a foreigner position that enables the assembly of a "heterogeneous archive" that makes visible the traces and persistence of the past. The book recovers from the idea of folding a logic that allows the concealment to be redefined as a renewed mode of exposure.

KEYWORDS: return, foreigner, photographies, archive, refugees.

\section{UN REGRESO CORAL}

Los sentidos del viaje a los orígenes o del regreso a la tierra de los antepasados suelen vincularse, por un lado, con una búsqueda de recuperación de una plenitud identitaria que, por uno u otro motivo, el retornante no podía lograr sino a través de ese ansiado desplazamiento. Esta modalidad del viaje parece suscitar, siempre como horizonte, la restauración de una unidad perdida, un encuentro con una verdad oculta, el desciframiento de una herencia que necesitaba del desplazamiento para efectuarse. Por otro lado, si otra cosa caracteriza también a las narrativas de regreso es la decepción: el modo en que responden, en mayor o menor medida, a la imposibilidad de volver a casa. El regreso siempre es promesa, pero también imposibilidad.

En el caso de La tierra empezaba arder (2019) de Cynthia Edul ${ }^{1}$, la escritura aprovecha el vaivén del regreso, el modo en que ese desplazamiento produce una desestabilización de la identidad y habilita un 
quiebre en la "corteza del tiempo" (2019, p. 31). El regreso abre la mirada transtemporal, una singular perspectiva que se hace eco de otros tiempos y visibiliza sus huellas. Esta novela cuenta el viaje a Siria que la escritora y dramaturga argentina Cynthia Edul realiza con su madre en octubre del 2010 para encontrarse con una parte de su familia cuya historia se trama en el ir y venir incesante entre Damasco y Buenos Aires. Este viaje a la tierra natal, a un universo árabe que resulta para la autora familiar y extraño a la vez, significa no solo la oportunidad de indagar en los conflictos y la intimidad del pasado familiar, sino también la de registrar el modo en que el régimen de Bashar Al-Assad permea tanto la vida pública como la cotidianeidad. La visita de Edul, realizada unos meses antes del estallido, la guerra civil y el recrudecimiento de la represión del régimen, permite construir un testimonio, reflexiona la autora, de un mundo que ya no existe más. Edul trama la memoria de la familia (actualizada mediante fotos y recuerdos) con una memoria social delineada a partir de paisajes ensayísticos sobre el mundo árabe y referencias a noticias, videos y textos de las redes sociales ${ }^{2}$.

En lo que respecta al trabajo, en el marco de las narrativas de regreso, la novela conecta la condición fantasmal e inestable del retornante -literal y metafóricamente, un revenant, un aparecido (Molloy, 2015, p. 18)-, su insistencia en lo que ya no existe, con una cuestión urgente del presente: la que sufren los migrantes, los refugiados, las víctimas del terror sistemático, los desposeídos de sus hogares, sus derechos, sus vidas. Dos imposibilidades del retorno diferentes: la que concierne -en buena medida- a toda vuelta, y la que sufren los que dejan atrás un escenario de desastre absoluto. Si bien, en esta novela, es el relato familiar lo que permite conectar el drama íntimo y el desastre humanitario, social y político, la escritura no descansa en esta relación como algo que simplemente puede exhibirse, como algo dado, sino como un producto de un trabajo, una labor de la mirada, una disposición poética y, al mismo tiempo, un impulso explicativo que busca visibiliza $\mathrm{r}$, reponer causas, rastrear datos históricos, establecer redes, comprender. La amalgama que la novela logra entre estos dos tonos (el lírico e intimista, el ensayístico y global) es producto de un ida y vuelta de la escritura, pero también de una particular inteligencia narrativa. Esta operación permite acceder a una intimidad, que en línea con lo que plantean Geraldine Pratt y Victoria Rosner en "The global and the intimate" (2006), no queda reducida a la esfera privada, sino que se trata más bien de una intimidad expandida, conectada con el afuera: lo estatal, lo político, lo cultural, el mundo. Sin embargo, para ser más precisos, habría que comprender cómo el libro de Edul responde no tanto a la dinámica de la expansión ${ }^{3}$, sino, más bien, a la de la superposición o pliegue. Al fin y al cabo, el regreso no es otra cosa que una suerte de pliegue del viaje ${ }^{4}$.

La novela abre con una frase de la tía que funciona como el origen de la escritura, pero también es su fantasma, un espectro que emerge entre las ruinas - como el que aparece frente al conde de Volney ${ }^{5}$ - y que en este caso impone una tarea de escritura: "La Siria que vos conociste ya no existe más" (Edul, 2019, p. 9). Frase que cierra y abre: indica la clausura de un espacio, de una experiencia, su inaccesibilidad, su desaparición, pero, al mismo tiempo, remite a la posibilidad de evocación, de expansión de los sentidos de un viaje, un regreso de la narradora, pero también de su madre, tres años atrás. La frase de la tía es contundente por su capacidad de condensación, por su modo de vincular diferentes tiempos: por un lado, un pasado inmediato (el del viaje) que a su vez se funde en el pasado familiar y en el de los antepasados y, por otro, un presente de urgencia, de violencia y de muerte. La narradora lo señala al principio de la novela y al hacerlo explicita la tarea asumida, una forma de respuesta de la escritora ante un presente de devastación: desde ese punto, ella "tiende los hilos" que construyen una trama transtemporal que encuentra su razón en el movimiento de ida y vuelta, de regreso.

Es preciso detenerse en esta cuestión en la medida en que está subrayada en el subtítulo del libro: "Último regreso a Siria". No se trata solo del relato de un regreso a la tierra de los antepasados que se revela como el último, sino también de las narraciones del retorno de la madre, del retorno del primo, el de la abuela, el de la tía: todos con diferentes motivaciones, todos con su singularidad, pero construyendo una suerte de "regreso coral" que funciona como una frecuencia que la novela sintoniza. Narrar la historia familiar es narrar sucesivos regresos, superpuestos, solapados, trenzados. Significa comprender que la familia está hecha de regresos, es decir, que algo constitutivo de lo familiar toma forma o se aloja en ese ida y vuelta. 
Esto permite entender por qué esta novela de "vuelta a los orígenes" no adquiere la forma de recuperación de una identidad o de un legado pleno. El núcleo de lo familiar, si bien está asociado a una tierra, a una tradición, a una cultura como la árabe y a la ley del desierto, también está vinculado y, no en menor medida, a ese lugar inestable, ese descalabro del arraigo que significa el abandono de la tierra y el intento de retorno. La historia familiar es la historia del desajuste entre hogar y experiencia: "Los regresos habían tejido la trama familiar, para conservar el espíritu nómade que estaba en los orígenes de nuestro clan” (Edul, 2019, p. 22). Regresar no es recuperar algo propio, tanto como volverse un poco -casi como un eco borgeano- el otro que antes regresó. Integrarse a la trama familiar es vivir esa no correspondencia, esa no pertenencia, ese estado de inquietud del retornante. Integrarse a lo familiar es desintegrarse un poco. Cada retorno es un punto de vista, una experiencia de desajuste, un trauma y su posibilidad de reparación. El retorno de la tía (la lucha en el juicio de sucesión), el de la madre (relevante para pensar los cambios en la sociedad árabe en los últimos tiempos) son muy distintos al regreso del primo quien luego de su vuelta "se aferró a las costumbres más conservadoras de la tierra natal" (Edul, 2019, p. 23).

Un retorno que la novela recupera con particular énfasis por medio de fotos, pero también de un trabajo de exploración ficcional es el regreso de la abuela. La abuela "enloqueció joven" y cuando comenzaron sus primeros ataques en Argentina, leemos, decidieron llevarla de vuelta a Siria bajo la idea de que ese viaje iba a oficiar de sanación. La abuela completa el triángulo de mujeres que gravitan sobre la narración y sobre la identidad familiar de la narradora. Es significativo el modo en que la novela trata la relación de las mujeres y la herencia como problema. Por un lado, a las hijas les corresponde menos de la mitad de la herencia material que a los varones, según el código de la sharī\#ah, lo que lleva al juicio por la sucesión que emprende la tía. Por otro, la abuela enloquece y opta por el silencio. La narradora enfrenta entonces el desafío de que la herencia para las mujeres esté atravesada por la pérdida del juicio. La figura de la abuela resulta central no solo por lo "no dicho", el secreto que guarda en su locura y en su silencio, sino porque su caso es un ejemplo claro de un entre lugar, un estado de intemperie que, en lugar de solucionarse con el regreso, se intensifica. La vida de la abuela demuestra que el regreso no puede pensarse como ejercicio de reparación de ningún tipo: “¿La tierra puede curar las heridas que dejó el haber sido expulsado de la tierra?” (Edul, 2019, p. 51). Cuando retorna a su tierra, la abuela insiste en preguntar: “¿Cuándo volvemos a casa?”. La narración asedia la historia de la abuela como un modo de afianzar el reconocimiento de la narradora en ese estado fantasmal de la retornante que ya no tiene hogar ni allá ni acá. En un pasaje, la narradora, excluida de la conversación familiar en árabe, lengua que no habla, se siente invisible y sale de la casa. Una vez fuera se pone a mirar el pueblo a la distancia, la cordillera, el desierto, y la nostalgia la invade. De pronto, se ve ante su abuela. El encuentro con esa imagen (sucedáneo espectral de la contemplación de las fotos), ese estar frente a frente no se construye como la confirmación de una identidad que condensa en la abuela una figura en la cual reflejarse, sino, más bien, como la posibilidad de la enunciación compartida de una interrogación: “QQuiénes somos? ¿Qué fue de todo esto?” (Edul, 2019, p. 127). La novela construye así la importancia de la mirada lateral, de este estar al margen, de este pertenecer, pero al mismo tiempo no. Como si la narradora siempre guardara un resto de no pertenencia o de extranjería que ya no funciona como el peso de una exclusión, o un posicionamiento impuesto desde el exterior -sos una expatriada, le achaca el primo como una imposición-, sino un lugar incómodo que combina distancia y cercanía, central para explicar la novela y los materiales que la componen ${ }^{6}$.

\section{El PLIEGUE DEL VELO}

Una particular reflexión sobre el uso de la hijab que la narradora expone viene a resignificar el modo de entender el uso del velo por parte de las mujeres árabes y permite leerlo ya no como un acto de sumisión al poder masculino, sino como un gesto de afirmación de la propia cultura: "Desde que empezó el ataque a los árabes, las mujeres se volvieron a cubrir. Es una forma de defender su identidad” (Edul, 2019, p. 47). Los rostros de las mujeres se sustraen así de un espacio público invadido por las fotos del presidente que 
se multiplican por todas partes y obligan a una suerte de familiaridad no buscada: "De tanto verlo ya me resultaba familiar” (p.59). El viaje permite el contacto pero también el close up (un acercamiento que habilita la mirada sobre el detalle), por medio del cual se devela una multiplicidad de sentidos que se alojan en los dobleces de la tela misma con la que las mujeres se cubren el rostro: "como los pliegues del velo se plegaba el sentido" (p. 47). Cuestión significativa no solo porque ubica la posibilidad de proliferación del sentido y del gesto político en una prenda que combina exhibición y ocultamiento, sino también porque desvía la asociación inmediata entre rostro e identidad. Lo oculto puede volverse así rasgo definitorio, cualidad representativa: de ahí que Damasco encuentre en "secreto y solapado" los adjetivos que "mejor representaban a esa ciudad” (p. 45). En línea con el concepto de táctica, tal como lo plantea Michel De Certeau ${ }^{7}$, las mujeres niegan la visibilidad pública de una parte de sí y enuncian a través del velo un paradójico "acá estamos" en términos culturales y religiosos. La táctica resulta el término apropiado para designar este gesto ya que si bien su carácter político nace del rechazo de un dominio o poder (el del gobierno de su país, el de Occidente), su acción se ve condicionada al terreno impuesto por esa ley o fuerza ajena. Si la experiencia urbana es la de la confrontación con los rostros entre los cuales la narradora busca una identificación, la dinámica de ocultamiento de sí como afirmación, le revelará, en primer lugar, que la identidad se dirime en un régimen de visibilidad tensionado entre lo privado y lo público, y en segundo lugar, que el ocultamiento puede ser también una forma de exposición.

La explicación sobre el valor político y religioso del uso del velo por medio de una contextualización histórica se cierra con una fotografía significativa que no es la de una mujer con la hijab, sino la de un conjunto de cabezas de maniquíes sobre las que se exhibe esta prenda en distintos tipos de tela y diseños. A través de esta imagen, el libro apunta a otra forma del reparto de lo visible en el espacio urbano: la de la prenda como mercancía en exhibición que se ofrece a los ojos de los transeúntes. Varias páginas después la escritora aborda aquello que ya vimos:

Una cabeza al lado de la otra, en filas, como una multitud enmudecida, sin rostro y sin identidad. Algodón o seda, la confección de los tejidos y los tapices que atravesaba la vida comercial de mi familia podía acaso remontarse ahí. Miraba esas cabezas de fibra, todas tenían el mismo rostro y la misma expresión y pensé si yo podría haber sido una más, entre todas. (Edul, 2019, p. 66).

Es en el objeto y sus características, y no en el rostro vislumbrado en la calle, donde se encuentra un reconocimiento de lo familiar. Lo propio se rescata entre los hilos del tejido y en el lugar de la prenda como mercancía que alude a la historia comercial de la familia. Sin embargo, lo curioso aquí es la convivencia entre este reenvío hacia lo familiar y una pulsión de despersonalización de ese yo que en lugar de mostrarse y reconocerse, duda, se vacía de rasgos y especula sobre la posibilidad de ser una más entre las cabezas sin expresión.

El libro aprovecha la lógica que ofrece la materialidad del velo en su plegado, el doblez, o superposición de dos planos (lo global y lo íntimo, las diferentes temporalidades, lo social y lo familiar, lo personal y lo impersonal), sumado al gesto de mostrar a través de un ocultamiento. De ahí que la tarea que emprende Edul no se reduzca en la mera visibilización de identidades, historias, conflictos en un momento de urgencia política y social, sino que consista, también, en trabajar con el silencio y la persistencia no visible del pasado como una forma potenciada de afirmación. Lógica que se apre(he)nde de la materialidad del velo, pero también de las edificaciones y sus junturas, sus superposiciones de piedras sobre piedras que permiten entender cómo "el presente se apoyaba sobre el pasado" (Edul, 2019, p. 105). Las ruinas son también un pliegue: allí el mundo material se postula como huella que evoca la persistencia de una dimensión inmaterial, fantasmal que deambula entre nosotros. El ocultamiento por medio del plegado que opera de forma más evidente el texto es el de varias fotografías que se mencionan pero que no integran el grupo de imágenes del álbum familiar y del diario de viaje, parecen, más bien, fantasmas escondidos en los pliegues de la escritura. 


\section{EL ARCHIVO Y EL PLIEgUE FOTOGRÁFICO}

Un impulso de archivo (Forster, 2016) ${ }^{8}$ funciona como motor de un libro que intercala las fotografías de viaje de la autora / narradora y su madre (sacadas con una Kodak de viaje comprada en el aeropuerto) con fotos del álbum familiar e imágenes subidas a las redes sociales. La reunión y entramado de estas fotografías de orígenes diversos es la propuesta de construcción de un archivo que reconfigura e interroga los límites mismos de las estructuras de archivo. Así como el álbum de familia adquiere una significación política, el material en internet adquiere ecos en la historia familiar. El libro constituye la narración de la búsqueda y construcción de un "archivo heterogéneo", un esfuerzo de montaje que incluye además de las fotografías ya mencionadas, posts de Facebook, fotogramas de videos de YouTube, anécdotas del mundo familiar, lecturas y análisis sociológicos e históricos, pero también pasajes bíblicos. El entramado de diversas perspectivas parecería nacer de una falta: la imposibilidad de hacer un testimonio en nombre propio, una distancia insalvable que radica justamente en el lazo familiar: el ser "hija de", tener "familia en". El lazo como lo que une, pero también como lo que separa. La narradora confiesa que esta falta le dificulta autorizarse para contar, siente que su condición es estar "de prestado". Justamente la potencia política del libro viene del "estar de prestado" que da lugar a una autorización dividida, incompleta, que, por un lado, se apoya en una relación mediada -que podría pensarse en línea con el concepto de postmemoria de Hirsch (2012) ${ }^{9}$-, una pertenencia distante, pero que, por otro, lleva a la necesidad de reforzarse con un trabajo que excede a la narrativa familiar. Tal autorización sostenida por dos vías es lo que le permite a la escritura moverse y anudar lo íntimo y lo social, lo privado y lo público, sin cerrarse, elevando una voz que explora los pliegues de lo cultural y lo identitario. El montaje de elementos diversos conforma un archivo que resulta familiar y global, al mismo tiempo, y adquiere pleno sentido en un horizonte de destrucción y catástrofe (Mendoza, 2019). Cuando las personas y su mundo desaparecen se vuelve imprescindible buscar formas y técnicas de perdurabilidad y persistencia: como la de los sahrawis, que a modo de resistencia y preservación de la memoria de la comunidad mantenían el nombre de sus pueblos dentro del campo de refugiados (Edul, 2019, p. 227).

Si nos detenemos en el uso del álbum familiar, observamos que las fotos de la familia, que suelen estar asociadas a un valor identitario y funcional como índice de la unidad familiar en el mundo moderno (Bourdieu, 2003, p. 28), entran también en una dinámica en la que paradójicamente integrarse en lo familiar consiste, como ya fue señalado, en una forma de desintegración. Las fotos familiares no se incluyen en el libro para exponer una identidad como certeza, sino como trabajo con lo disputado, lo incierto y lo incompleto. Por ejemplo, la fotografía de la página 57 que tiene debajo como pie de foto la descripción "Familia en Siria, 1957 " es una imagen con la función clara de cohesionar, en la que un grupo de personas posan para conformar un todo. Pero esta foto se yuxtapone en el entramado del libro con la narración de los conflictos y disputas por la herencia, a una experiencia de sucesión dividida entre Siria y Argentina. Imagen y texto se distribuyen aquí la tensionada tradición familiar de división y unidad, conflicto y enlace. En muchos casos, la narración construye imágenes familiares de las cuales no sabemos si tienen o no un respaldo fotográfico. La imaginación narrativa cubre los huecos de la historia familiar allí donde no hay fotos que testimonien o se expande sobre aquello que la foto oculta al mostrarse. En la página 115 una descripción antecede a la foto de tres mujeres. El texto repone que una de ellas es la abuela y exhibe la brecha entre lo que es posible ver en la imagen y lo que el relato antes reconstruyó. "La mirada despejada. No veo signos de perturbación en sus ojos" (Edul, 2019, p. 115). La fotografía entonces se observa en la confluencia de tiempos. De esa manera, la foto no es un simple objeto que activa el recuerdo, sino un elemento que se actualiza cada vez que se lo hace aparecer. Cuando la foto vuelve a "decir" lo que dice lo hace por primera vez en una actualización que a su vez no deja de portar una irradiación fantasmática de lo que pasó (Russo, 2011). En La tierra comenzaba a arder la foto familiar se saca del fuero íntimo para renarrarse y propiciar así una incorporación al relato social. Pero este movimiento se hace, sobre todo y paradójicamente, con las fotos que no se exhiben. La foto que se nombra pero que no se muestra establece el pliegue de exhibición a través de un ocultamiento que separa y une lo familiar y lo 
político. Cuando las noticias de la destrucción y la masacre en Siria comienzan a llegar y se menciona a un familiar secuestrado, la narradora vuelve sobre una foto que sacó en el viaje para darle rostro al "hijo de la tía Nela”. El gesto de buscar en el álbum aquella en la que aparece "el hijo de la tía Nela, la hermana de la abuela, único pariente vivo de una generación casi extinguida” (Edul, 2019, p. 149) recupera el recuerdo de esa visita a la familia de la abuela en Yabrüd, pero sobre todo permite afirmar una relación allí donde la distancia amenaza con dividir, con diluir los lazos. El álbum familiar le pone rostro a la violencia lejana, pero ese rostro -como el de las mujeres árabes- queda oculto. Ese ocultamiento detiene el efecto de particularización de la experiencia, evade la fijación de la identidad en un rostro concreto. La foto primero se menciona como documento, luego se busca y se encuentra cuando la narradora propone "armar el identitik" (Edul, 2019, p. 148), pero nunca se exhibe en la serie de imágenes que componen el libro. En su lugar, tenemos las fotos de una "tarde luminosa y plena" de octubre de 2010 en Yabrüd en las que no se ve nadie, que contrastarán luego -mediante otro pliegue del libro- con los fotogramas de un video de YouTube de los enfrentamientos bélicos y la destrucción en ese mismo pueblo. Si bien, por un lado, se personaliza y visibiliza la historia personal del hijo de la tía, al mismo tiempo, se la abre a una potencia de impersonalidad al no quedar anclada en una imagen individual. En su ausencia, el rostro no exhibido permite conectar con lo anónimo, con un destino colectivo que ya no se sostenga en la exhibición privilegiada de una subjetividad o una individualidad. La singularidad de la operación de Edul radica en el doble movimiento de identificación y ocultamiento de los rasgos aludidos. La materialidad del velo y su uso permiten entender esta lógica en la que el ocultamiento se vuelve instrumento de una forma renovada e intensa de aparición. De esta manera, se evoca una vida impropia,

en el sentido de que en ellas la vida no se define por su pertenencia a alguien en particular, a un sujeto, sino en tanto energía o "spark", en palabras de Dickens, que trasciende esos sujetos. Más allá, incluso, de los cuerpos individuales (Garramuño, 2018, p. 1).

Las fotografías propician, además, otro pliegue que funciona articulando el documento familiar y el drama político mediante la materialidad que ponen en primer plano. La foto que la narradora se saca en 2010 de un cartel que presenta un valor familiar (mostrar la entrada del pueblo de los abuelos) permite una conexión con un video en YouTube que muestra un enfrentamiento en Yabrüd en el que se produce un reencuentro con la imagen del cartel, en este caso, acribillado. La inmaterialidad global de los fotogramas del video subido a internet se materializa en el libro impreso como portadora de la huella (material) de la violencia y destrucción de parte del mundo de la memoria familiar. La fotografía sin materialidad que circula en las redes sociales y la fotografía como soporte material de un álbum familiar se yuxtaponen y superponen en el libro para construir una perspectiva transtemporal, de manera tal que la idea de un tiempo lineal y progresivo queda acribillada por esas huellas que persisten y emergen de las fotos entendidas como cúmulo de señas puestas en relación.

\section{CoMentarios FinALES. LA CASA DEL EXTRANJERO}

A partir del vaivén entre la foto familiar y el video de YouTube, entre la voz de la amiga de la madre y el post de Facebook, la novela se carga al hombro una cuestión ética clave en un presente de pérdida y devastación, en un momento donde ya no hay mundo como horizonte posible de solución o de intervención. En el pliegue de diferencia y solapamiento entre el “¿dónde está la casa?” de la abuela y “¿el mundo dónde está?” que repite la madre de la narradora, la pregunta sostenida sobre otras interrogaciones es una preocupación de cuño cosmopolita: cómo hacer significativa la relación con un otro que está lejos, que puede ser familiar o vinculado a lo familiar, pero que, en la mayoría de los casos no lo está, es decir, un otro que es distancia máxima, que se encuentra en un "allá" desconocido, inalcanzable, incluso inimaginable para muchos ${ }^{10}$. Para lograr esto, la narradora se ubica en una posición incómoda, un umbral entre la pertenencia y la extranjería que, en definitiva, es lo que posibilita el entramado particular que constituye la novela, esa sutura singular entre lo íntimo y lo global, entre lo personal y lo impersonal. En este caso, hacer un viaje hacia lo propio, hacia el 
origen, no lleva a cerrar o definir en términos estáticos una identidad, sino más bien a instalarse en una que se asume como perplejidad, lo cual no significa el despojamiento o el rechazo respecto de esa tradición familiar, de esa cultura árabe que el texto recupera e incorpora a su entramado, sino más bien, una apropiación que no anula el interrogante, el cuestionamiento, la mirada lúcida sobre matices, disidencias, contradicciones. Así como la inmersión en la historia familiar entendida como trama de regresos significa además de recuperar una memoria, instalarse en un lugar inestable, en un espacio imposible entre la ida y la vuelta, la mirada sobre la tradición árabe significa encontrar en ese rumor ancestral, en esa herencia una clave para pensar una relación con el extranjero. A contramano de los cierres y esencialismos identitarios y la lógica sectaria que alimenta la discordia entre hermanos, la segregación, la guerra, la novela recupera en un momento los versos del poeta preislámico Imru al Qais: “todo extranjero para el extranjero es mi pariente” (Edul, 2019, p. 90). Ir hacia lo propio para descubrirse extranjera, pero también para descubrir en lo propio una clave de la relación con lo extranjero. Lo ancestral se conecta con la urgencia del presente, lo antiguo, un eco de otro tiempo, da una respuesta hoy, cuando nadie da respuestas. El libro de Edul se enmarca en un momento en el que, como señalan Marianne Hirsch y Nancy Miller (2011), la búsqueda de las raíces se imbrica con la existencia diaspórica, los desmembramientos familiares, la dispersión e irrecuperabilidad de los legados culturales. Como se ha demostrado en este trabajo, tal imbricación entre uniones y desencuentros se produce a través de una escritura que aprovecha el vaivén del viaje de regreso desde un lugar de enunciación incómodo que construye y exhibe su extranjería para que la misma funcione como condición clave para explicar la misma forma de la novela y los materiales que la integran. La posición de extranjería propuesta por Edul toma forma a través de la lógica del pliegue que, como hemos visto, opera sobre el borde de diferencia y enlace de lo público y lo privado, lo familiar y lo ajeno, lo oriental y lo occidental para volver un espacio sobre el otro, una y otra vez. Bajo la idea de pliegue hemos precisado la operación de ocultamiento de una serie de fotografías mencionadas en el libro sin estar acompañadas por un movimiento de exposición. Así los rostros familiares no exhibidos adquieren una potencia vinculada a lo anónimo, así la materialidad del álbum se combina con la inmaterialidad de la fotografía en las redes para construir una mirada transtemporal. En la "era del refugiado", La tierra empezaba a arder propone, a partir de los pliegues de la exploración íntima, el ensayo históricosocial y la indagación poética, esbozar y repensar formas de supervivencia cuando ya no hay casa ni mundo que responda o pueda proteger de alguna manera.

\section{Bibliografía}

Anderson, A. (2001). The Powers of Distance: Cosmopolitanism and the Cultivation of Detachment. New Jersey: Princeton University Press.

Bourdieu, P. (2003). Un arte medio. Ensayo sobre los usos sociales de la fotografía. Barcelona: Editorial Gustavo Gili.

De Certeau, M. (2000). La invención de lo cotidiano: Artes de hacer. México D. F.: Universidad Iberoamericana.

Deleuze, G. (1989). El pliegue. Barcelona: Paidós.

Edul, C. (2019). La tierra empezaba a arder. Buenos Aires: Lumen

Forster, H. (2016). El impulso de archivo. Nimio, (3), 102-125.

Garramuño, F. (2018). La vida impropia. Corpus, 8(2), 1-6. Recuperado de http://journals.openedition.org/corpusa rchivos/2716

Giunta, A. (2009). Extranjería y nuevas pertenencias en las artes visuales. En Garcia Canclini, N. (Comp.), Extranjeros en la Tecnología y en la Cultura (pp. 39-50). Buenos Aires: Fundación Telefónica/Ariel.

Hirsch, M. (2012). The generation of postmemory: writing and visual culture after the Holocaust. New York: Columbia University Press.

Hirsch, M. y Miller, N. K. (Eds.). (2011). Rites of return: diaspora poetics and the politics of memory. New York: Columbia University Press. 
Kearney, R. y Semonovitch, K. (Eds.). (2011). Phenomenologies of the stranger: Between hostility and hospitality. New York: Fordham University Press.

Krauss, R. (2002). La escultura en el campo expandido. En Foster, H. (Coord.). La posmodernidad (pp. 59-74). Barcelona: Kairós.

Mendoza, J. J. (2019). Los archivos. Papeles para la nación. Villa María: Eduvim.

Molloy, S. (2015). Dislocación e intemperie: el viaje de vuelta. Caracol, (10), 18-37.

Pratt, G. y Rosner, V. (2006). Introduction: The global \& the intimate. Women's Studies Quarterly, 34(1), 3-24.

Russo, S. (2011). Foto, identidad y performance, en Boca de Sapo. Revista de arte, literatura y pensamiento, (11), 38-41.

Simmel, G. (2012). El extranjero. En: AAVV. El extranjero: sociología del extraño (pp. 21-26). Madrid: Ediciones sequitur.

\section{Notas}

1 Cynthia Edul (Argentina, 1979) es novelista, dramaturga y directora de teatro. Es licenciada en Letras por la Universidad de Buenos Aires (UBA) y en Dramaturgia por la Escuela Municipal de Arte Dramático (EMAD), profesora del Departamento de Humanidades de la Universidad de San Andrés. En 2009 creó, junto con Alejandro Tantanian, la plataforma de dramaturgia contemporánea Panorama Sur. Recibió las becas para escritores de la Universidad de Iowa (EE. UU.), de Courants du Monde (Francia) y de la Saison Foundation de Tokio (Japón). Entre 2016 y 2017 dirigió Teatro Argentino - Centro de Experimentación y Creación (TACEC). En 2018 coordinó el programa "Produce en el país" del Teatro Nacional Cervantes y dirigió la pieza Las rotas, de Nadine Lifchitz.

2 En cuanto al encuadre genérico de la propuesta de Edul debe precisarse que el trabajo de su novela se inserta en el plano de la autobiografía en un cruce con la non-fiction novel (dado su trabajo con materiales como testimonios y documentos). De esta manera, su apuesta novelística apunta al entrecruzamiento entre la memoria familiar y la memoria social sin dejar de lado la preocupación por el trabajo con el lenguaje y la construcción literaria de una voz.

3 En la sugerencia de considerar la propuesta de Edul como un trabajo con una intimidad expandida, resuena la noción de "campo expandido" para hablar de la ampliación de las coordenadas de las prácticas artísticas. De esta manera, explica Rosalind Krauss (2002), el artista dispone de una serie expandida de posicionamientos para explorar sin las limitaciones de un medio particular. Así podríamos pensar aquí una intimidad ampliada que expande su campo de acción sobre planos que la exceden (la política, lo estatal, lo social) aunque en realidad, veremos, lo íntimo se confrontará y superpondrá con otras dimensiones siguiendo, más bien, otra lógica: la del pliegue.

4 El uso que se hace aquí del término "pliegue” remite a la concepción deleuziana. Deleuze (1989) utiliza esta noción para dar cuenta del aporte por excelencia del barroco. La duplicidad del pliegue, señala Deleuze, se reproduce "en los dos lados que el pliegue distingue, pero que, al distinguirlos, relaciona entre sí: escisión en la que cada término remite al otro, tensión en la que cada pliegue está tensado en el otro" (p. 45). El libro de Edul reproduce esta función operatoria que describe Deleuze cuando trabaja sobre la diferencia (lo público y lo privado, lo familiar y lo extraño, el mundo oriental y el occidental, lo íntimo y lo social) y a su vez, une y lanza estos espacios o lados separados uno sobre el otro en ese mismo gesto de escisión. Frente a la expansión correspondería a una lógica de proliferación dentro de un mismo mundo o "plano de inmanencia" en la que no existe ningún repliegue o puesta en relación entre dos regímenes diferentes: por ejemplo, un libro arraigado en lo político o en lo íntimo entendidos como planos o esferas aisladas.

5 Volney formó parte de la llamada segunda generación de los ideólogos franceses en cuya obra convergen el racionalismo iluminista y los ideales de la Revolución Francesa. A fines de 1782, Volney realizó un viaje a Egipto y cercano Oriente. En su estadía en Siria, aprovechó para visitar diversas ciudades y regiones. Un sitio histórico en particular inspiró su libro de 1791, Las ruinas o Meditación sobre las revoluciones de los imperios, también conocido como Las ruinas de Palmira (nombre con el que se conocerá su obra en el mundo hispanohablante). La referencia establecida aquí corresponde a este libro.

6 Frente a la tradición sociológica que inicia Georges Simmel (2012) y que le asigna al extranjero una "objetividad" en la combinación de indiferencia y compromiso, veremos que el trabajo narrativo de Edul explota, más bien, la potencialidad de lo extranjero (foreign) como un posición vinculada con lo extraño (stranger), es decir, con una condición entendida como fuerza de indefinición que rehuye de las catalogaciones y clasificaciones que impone la cultura (Kearney y Semonovitch, 2011). La extranjería opera aquí de manera similar a lo que Andrea Giunta (2009) llama "extranjería situacional" para pensar el arte contemporáneo y que consiste en desclasificaciones que nacen de la mirada del otro o que el mismo artista activa para exhibir una extrañeza. Este concepto permite desviarse de la idea de extranjería como 
efecto de una expulsión en términos nacionales para entender la transmutación de las distancias culturales o geográficas en capacidad innovadora.

7 La táctica, propone Michel De Certeau, es un cálculo o intervención en relaciones de fuerza que, a diferencia de la estrategia, carece de un lugar propio, no puede capitalizar ventajas y asegurar una independencia en función de las circunstancias. "La táctica no tiene más lugar que el del otro", afirma De Certeau (2000, p. 43).

8 Para Foster (2016), el «artista de archivo» se dedica a hacer presente información histórica perdida o soslayada para propiciar así la emergencia de elementos excluidos del relato historiográfico hegemónico o del relato familiar oficial.

9 El estudio de la postmemoria tal como lo propone Marianne Hirsch (2012) no atrae la atención sobre los sobrevivientes de las catástrofes y acontecimientos traumáticos, sino, más bien, sobre el modo en que las generaciones posteriores interrogan su pasado y los modos en que su transmisión se produce. Las vidas de hijos y descendientes dominadas por memorias que preceden a su nacimiento los lleva a reflexionar sobre su lugar y su experiencia ante las memorias familiares que permea su cotidianeidad. La postmemoria, plantea Hirsch, funciona como una "generational structure of transmission embedded in multiple forms of mediation" (2012, p. 35) en la que interviene la imaginación, la identificación y la proyección. El vínculo mediado que construye Edul en su libro tiene que ver con la acogida y afiliación de estos testimonios e imaginarios que anudan lo familiar, así como también con la pugna con los vacíos y fracturas en la memoria ocasionadas por los desplazamientos, olvidos y conflictos. Lo que distingue el trabajo y el posicionamiento de Edul es la necesidad de reconstruir y pensar una forma de relación no solamente con acontecimientos traumáticos del pasado, sino también con una catástrofe contemporánea.

10 A la hora de pensar la reconfiguración de la figura del cosmopolita, esta ya no se corresponde, como señala Amanda Anderson, con un universalismo gris sino con un vívido espectro de diversas dialécticas de distanciamiento, desplazamiento y afiliación. Se vuelve relevante, entonces, el vínculo con conflictos éticos específicos, y una actitud receptiva hacia el otro que estimule la recíproca conexión (2001). 